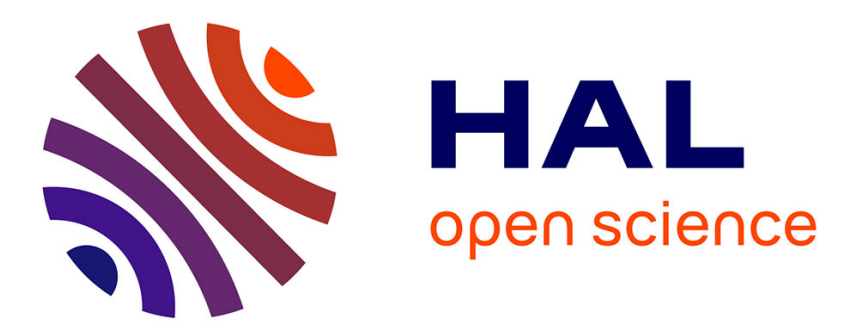

\title{
Charge-transfer complexes of sulfur-rich acceptors derived from birhodanines
}

\author{
Shuxiang Fan, Yasuhiro Kiyota, Kodai Iijima, Suho Ryo, Tadashi Kawamoto, \\ Yann Le Gal, Dominique Lorcy, Takehiko Mori
}

\section{- To cite this version:}

Shuxiang Fan, Yasuhiro Kiyota, Kodai Iijima, Suho Ryo, Tadashi Kawamoto, et al.. Charge-transfer complexes of sulfur-rich acceptors derived from birhodanines. CrystEngComm, 2019, 21 (35), pp.52275234. 10.1039/c9ce00952c . hal-02359976

\section{HAL Id: hal-02359976 https://hal-univ-rennes1.archives-ouvertes.fr/hal-02359976}

Submitted on 30 Mar 2020

HAL is a multi-disciplinary open access archive for the deposit and dissemination of scientific research documents, whether they are published or not. The documents may come from teaching and research institutions in France or abroad, or from public or private research centers.
L'archive ouverte pluridisciplinaire HAL, est destinée au dépôt et à la diffusion de documents scientifiques de niveau recherche, publiés ou non, émanant des établissements d'enseignement et de recherche français ou étrangers, des laboratoires publics ou privés. 


\title{
ARTICLE
}

\section{Charge-transfer complexes of sulfur-rich acceptors derived from birhodanines $\uparrow$}

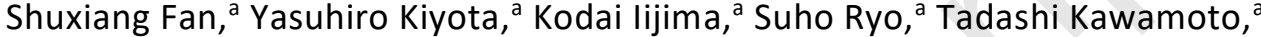 \\ Yann Le Gal, ${ }^{b}$ Dominique Lorcy, ${ }^{\mathrm{b}}$ and Takehiko Mori ${ }^{* a}$
}

Sulfur-rich acceptors, birhodanines, 3,3'-dialkyl-5,5'-bithiazolidinylidene-2,2'-dione-4,4'-dithiones (OS- $\boldsymbol{R}, R=\mathrm{Et}$ and $\mathrm{Pr}$ ) and 3,3'-dialkyl-5,5'-bithiazolidinylidene-4,4'-dione-2,2'-dithiones (SO-R, $R$ $=\mathrm{Et})$, as well as the sulfur analogues, 3,3'-dialkyl-5,5'-bithiazolidinylidene-2,4,2',4'-tetrathiones (SS-R, $R=\mathrm{Et}, \mathrm{Pr}$ ), form 1:1 composition charge-transfer complexes with donors such as pyrene, perylene, and coronene. These complexes have mixed stacks, and the SS- $\boldsymbol{R}$ complexes show $\mathrm{n}$ channel transistor properties due to the intercolumnar $S$...S contacts between the acceptors. By contrast, the OS- $\boldsymbol{R}$ and SO- $\boldsymbol{R}$ complexes exhibit basically hole-dominant ambipolar properties due to the absence of $S$...S contacts. Accordingly, the charge transport is governed mostly by the direct interchain interactions instead of the transport along the columns.

\section{Introduction}

Recently, we have reported n-channel transistor materials with excellent air stability: birhodanines, 3,3'-dialkyl-5,5'-bithia zolidinylidene-2,2'-dione-4,4'-dithiones (Scheme 1, hereafter abbreviated as OS-R), as well as the isomer, 3,3'-dialkyl-5,5'bithiazolidinylidene-4,4'-dione-2,2'-dithiones (SO-R) and their sulfur analogues, 3,3'-dialkyl-5,5'-bithiazolidinylidene-2,4,2',4'tetrathiones $(\mathbf{S S}-\boldsymbol{R}){ }^{1-3} \mathbf{S S}-\boldsymbol{R}$ is obtained in the course of developing single-component molecular conductors, ${ }^{4,5}$ and is a sufficiently strong electron acceptor to achieve air-stable nchannel transistors. OS- $\boldsymbol{R}$ and SO-R are a little weaker acceptors and the device air stability is slightly reduced. Despite their strong acceptor ability, these acceptors have been very little studied as precursor of charge transfer complexes. Only a ferrocene complex of SS-Et together with the ferrocene and tetramethyltetrathiafulvalene complexes of the dicyanomethylene derivative have been reported; ${ }^{5}$ these combinations exhibit mixed-stack structures.

However, there is recently an increasing interest in chargetransfer complexes of organic semiconductors. ${ }^{6}$ This is partly prompted by increasing attention to the carrier doping; ${ }^{7}$ formation of a structurally well-defined donor-acceptor (DA) cocrystal is unmistakable evidence of the charge-transfer interaction. Transistor properties of such charge-transfer complexes have been investigated, ${ }^{8}$ which are interesting in analogy with the recently developing high-performance DA polymers. ${ }^{9}$
Since DA complexes contain both D and A units, it is likely that DA cocrystals show ambipolar transistor properties. In mixed-stack complexes, both electron and hole transports are subjected to the same hopping process between the D highest occupied molecular orbital (HOMO) and the A lowest unoccupied molecular orbital (LUMO). When such a process is characterized by a transfer integral $t$ and energy difference $E_{\mathrm{L}}-$ $E_{\mathrm{H}}$, the effective electron and hole transfers are represented by $t_{\mathrm{e}} \mathrm{eff}^{\text {eff }} t_{\mathrm{h}}{ }^{\text {eff }} \sim t^{2} /\left(E_{\mathrm{L}}-E_{\mathrm{H}}\right)$, and should be the same. ${ }^{10}$ Nonetheless, many DA cocrystals show only n-channel transport, particularly in tetracyanoquinodimethane (TCNQ) complexes. ${ }^{8,11}$ This is because the D HOMO and the A LUMO are approximately orthogonal $(t \sim 0)$ due to the horizontal node of the $\mathrm{D}$ HOMO. ${ }^{12-15}$ The electron transport is usually mediated by the hybridization of the D next HOMO (HOMO-1), which has the same stripe symmetry as the A LUMO. There are no such "bridge" orbitals to mediate hole transport, and electron-only transport has been universally observed. ${ }^{13}$
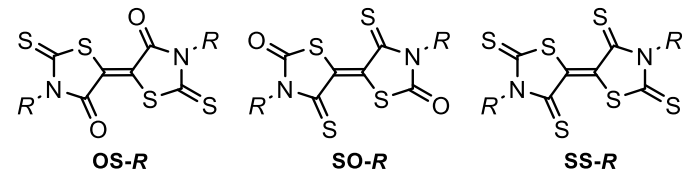

Scheme 1. Molecular structures, where $R=$ ethyl (Et), and $n$-propyl (Pr). 
(a)

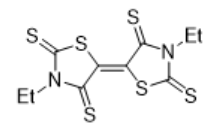

SS-Et

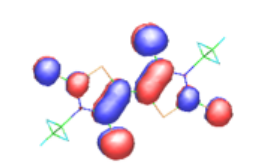

$-4.2 \mathrm{eV}$

LUMO $(-4.29 \mathrm{eV})$

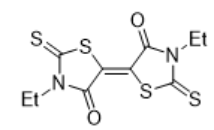

OS-Et

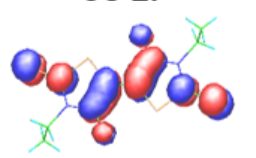

$-3.8 \mathrm{eV}$ $(-3.78 \mathrm{eV})$
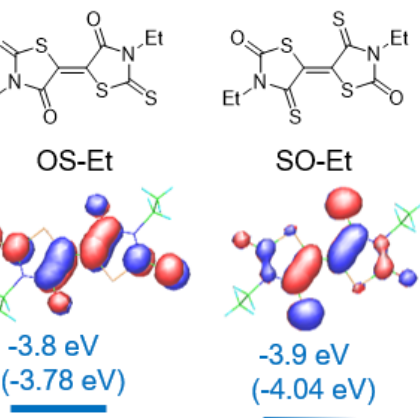

SO-Et

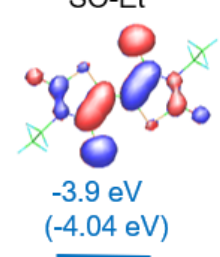

HOMO $\overline{-5.68 \mathrm{eV}}$ $(-5.47 \mathrm{eV})$
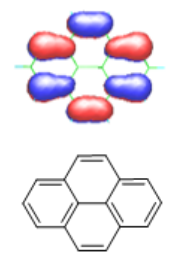

(b)

pyrene

$$
\overline{-5.38 \mathrm{eV}}
$$

$(-5.12 \mathrm{eV})$
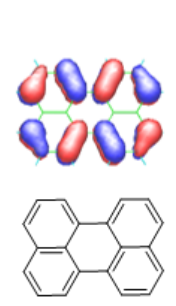

perylene
$-5.58 \mathrm{eV}$

$(-5.49 \mathrm{eV})$

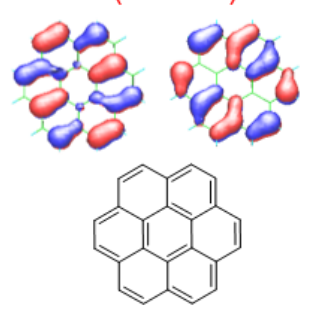

coronene (c)

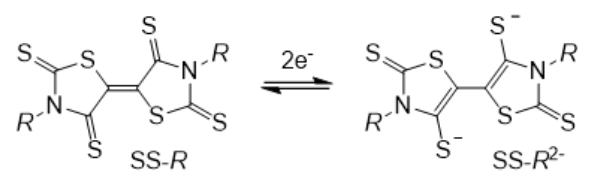

Figure 1. (a) Molecular orbitals of SS-Et, OS-Et, and SO-Et as well as (b) pyrene, perylene, and coronene. The energy levels are determined by cyclic voltammetry. $2,14,15$ The values in the parentheses are from the molecular orbital calculations. (c) Anionic form of SS- $\boldsymbol{R}$.

The present paper reports crystal structures and transistor properties of pyrene, perylene, and coronene (Fig. 1) complexes of SS- $\boldsymbol{R}$, OS- $\boldsymbol{R}$ and SO- $\boldsymbol{R}$ acceptors $(R=\mathrm{Et}$ and $\mathrm{Pr})$. These cocrystals have mixed-stack columns, though the details depend on the alkyl chains and donors. SS- $\boldsymbol{R}$ complexes exhibit electron-transporting transistor properties, whereas OS- $\boldsymbol{R}$ and SO- $\boldsymbol{R}$ complexes show basically ambipolar transistor properties. The transistor properties are discussed by investigating the intermolecular interactions.

\section{Experimental section and calculation method}

The acceptor molecules were prepared according to the reported methods. ${ }^{2,5}$ The acceptors and the donors were independently dissolved in warm toluene, and the solvent of the mixed solution was slowly evaporated. After about three weeks, black needle-like crystals were harvested. Acceptors with $R=$ methyl, ethyl, $n$-propyl, and $n$-butyl were combined with various donors, among which crystals with sufficient quality were obtained for combinations listed in Tables 1 and 2.
Transistors were fabricated onto n-doped Si substrates with a thermally grown $\mathrm{SiO}_{2}$ dielectric layer $(300 \mathrm{~nm}, C=11.5 \mathrm{nF}$ $\mathrm{cm}^{-2}$ ). The passivation layer polystyrene (PS, $\varepsilon=2.5$ ) was deposited by spin coating (3000 rpm and $30 \mathrm{sec}$ ) a solution of PS $(20 \mathrm{mg})$ in toluene $(1 \mathrm{~mL})$ on the substrates with a thickness of $100 \mathrm{~nm},{ }^{16}$ where the calculated overall capacitance was 7.6 $\mathrm{nF} \mathrm{cm}{ }^{-2} \cdot{ }^{17}$ Needle-like black crystals were put on the PS layer using ethanol. ${ }^{18}$ Carbon paste (DOTITE, XC-12) was deposited on two ends of the single crystal to make the source and drain electrodes, and the crystal long axis was oriented in the channel direction. The single-crystal X-ray diffraction indicates that the crystal long axis is parallel to the molecular stacking axis. The transistor properties were measured under the vacuum of $10^{-3}$ $\mathrm{Pa}$ by using a Keithley 4200 semiconductor parameter analyzer.

Molecular orbital calculations in the B3LYP* level with TZP basis set were performed using the Amsterdam Density Functional (ADF) program. ${ }^{19}$ Direct AA/DD transfers were evaluated from the splitting of A LUMO/D HOMO in the AA/ DD dimers. Direct transfers were also estimated from the frozen orbital approximation. ${ }^{20,21}$ In the mixed stacks, $t_{\mathrm{e}} \mathrm{eff} / \mathrm{h}_{\mathrm{h}}{ }^{\text {eff }}$ was evaluated from the LUMO/HOMO splitting of an ADA/DAD triad. ${ }^{10,13} t_{\mathrm{e}} \mathrm{eff}^{\text {eff }}$ and $t_{\mathrm{h}}{ }^{\mathrm{eff}}$ were also obtained from the partition method according to the following equation. ${ }^{12,13}$

$$
t^{e f f}=\sum_{i} \frac{t_{0 i} t_{i 0}}{E_{0}-E_{i}}
$$

\section{Results and discussion}

\section{Energy levels and molecular orbitals}

Energy levels and molecular orbitals are shown in Fig. 1. SS- $\boldsymbol{R}$ is a strong electron acceptor with the LUMO level at $-4.2 \mathrm{eV},{ }^{2}$ which is sufficient to achieve air-stable n-channel transistors. This is because we can suppose an $\mathrm{S}^{-}$form for the anion as depicted in Fig. 1(c), where the LUMO is delocalized to the $\mathrm{C}=\mathrm{S}$ parts. OS- $\boldsymbol{R}$ and SO- $\boldsymbol{R}$ are a little weaker acceptors with the LUMO level at $-3.8 \mathrm{eV} \sim-3.9 \mathrm{eV},{ }^{2}$ and the transistor air stability is slightly reduced. Perylene and coronene are moderate electron donors, whereas pyrene is a weak electron donor. ${ }^{14,15}$ The resulting HOMO-LUMO gaps of the complexes are located in the range of $1.2-1.9 \mathrm{eV}$.

\section{Crystal structures}

$\mathrm{X}$-ray single-crystal structure analyses were carried out for five SS- $\boldsymbol{R}$ complexes $(R=$ Et and Pr) listed in Table 1 as well as three OS- $\boldsymbol{R}(R=\mathrm{Et}$ and $\mathrm{Pr})$ and three SO-Et complexes listed in Table 2. Perylene makes crystals with all these five acceptors.

These complexes have mixed stacks along the $b$ axis (Figs. 2-4). These crystals are, however, not strictly isostructural; the lattice angles are considerably different in the $\mathbf{O S}-\boldsymbol{R}$ complexes (Table 2). The DA interplanar spacings, listed in Tables 2 and 
Table 1. Crystallographic data of SS- $\boldsymbol{R}$ complexes.

\begin{tabular}{|c|c|c|c|c|c|}
\hline & $\begin{array}{l}\text { (pyrene) } \\
(\text { SS-Et) }\end{array}$ & $\begin{array}{c}\text { (perylene) } \\
(\mathbf{S S}-\mathbf{E t})\end{array}$ & $\begin{array}{c}\text { (coronene) } \\
(\mathbf{S S}-\mathbf{E t})\end{array}$ & $\begin{array}{l}\text { (pyrene) } \\
\text { (SS-Pr) }\end{array}$ & $\begin{array}{c}\text { (perylene) } \\
(\mathbf{S S}-\mathbf{P r})\end{array}$ \\
\hline Formula & $\mathrm{C}_{26} \mathrm{H}_{20} \mathrm{~N}_{2} \mathrm{~S}_{6}$ & $\mathrm{C}_{30} \mathrm{H}_{22} \mathrm{~N}_{2} \mathrm{~S}_{6}$ & $\mathrm{C}_{34} \mathrm{H}_{22} \mathrm{~N}_{2} \mathrm{~S}_{6}$ & $\mathrm{C}_{28} \mathrm{H}_{24} \mathrm{~N}_{2} \mathrm{~S}_{6}$ & $\mathrm{C}_{32} \mathrm{H}_{26} \mathrm{~N}_{2} \mathrm{~S}_{6}$ \\
\hline Formula weight & 552.82 & 602.88 & 650.92 & 580.87 & 630.93 \\
\hline Crystal System & triclinic & triclinic & triclinic & monoclinic & monoclinic \\
\hline Space Group & $P-1$ & $P-1$ & $P-1$ & $P 21 / n$ & $P 2_{1} / c$ \\
\hline Shape & block & block & block & block & plate \\
\hline$a(\AA)$ & $7.457(5)$ & $7.541(6)$ & $7.271(3)$ & $7.564(3)$ & $7.659(8)$ \\
\hline$b(\AA)$ & $7.942(8)$ & $8.263(6)$ & $9.426(9)$ & $7.574(6)$ & $8.117(6)$ \\
\hline$c(\AA)$ & $11.259(7)$ & $11.632(7)$ & $11.546(6)$ & $22.84(1)$ & $23.27(3)$ \\
\hline$\alpha$ (deg.) & $71.93(6)$ & $70.08(5)$ & $67.88(5)$ & 90 & 90 \\
\hline$\beta$ (deg.) & $74.01(5)$ & $75.07(6)$ & $74.83(4)$ & $96.90(3)$ & $96.74(8)$ \\
\hline$\gamma($ deg. $)$ & $89.57(7)$ & $89.43(7)$ & $79.16(5)$ & 90 & 90 \\
\hline$V\left(\AA^{3}\right)$ & $607.2(8)$ & $656.0(8)$ & 703.9(9) & 1299(1) & 1437(3) \\
\hline$Z$-value & 1 & 1 & 1 & 2 & 2 \\
\hline$T(\mathrm{~K})$ & 298 & 298 & 298 & 298 & 298 \\
\hline$D_{\text {calc }}\left(\mathrm{g} \mathrm{cm}^{-3}\right)$ & 1.512 & 1.526 & 1.535 & 1.485 & 1.459 \\
\hline Total reflns. & 4199 & 4554 & 4808 & 4500 & 4828 \\
\hline Unique reflns. $\left(R_{\text {int }}\right)$ & $3545(0.0592)$ & $3836(0.0985)$ & $4116(0.0463)$ & 3792 (0.0219) & $4201(0.0255)$ \\
\hline$R_{1}\left[F^{2}>2 \sigma\left(F^{2}\right)\right]$ & 0.0454 & 0.0530 & 0.0538 & 0.0401 & 0.0556 \\
\hline $\begin{array}{c}w R_{2} \text { [All } \\
\text { reflections] }\end{array}$ & 0.1323 & 0.1543 & 0.1582 & 0.1144 & 0.1656 \\
\hline GOF & 1.020 & 0.999 & 1.000 & 1.050 & 0.927 \\
\hline DA spacing $(\AA)$ & 3.47 & 3.50 & 3.49 & 3.51 & 3.52 \\
\hline$S \cdots S$ contacts $(\AA)$ & $4.06,4.08$ & 3.59 & 3.56 & $3.90,4.08$ & 3.96 \\
\hline
\end{tabular}

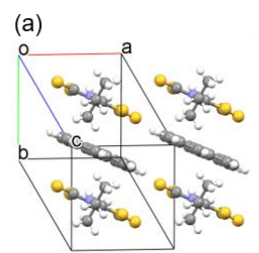

(b)

(c)
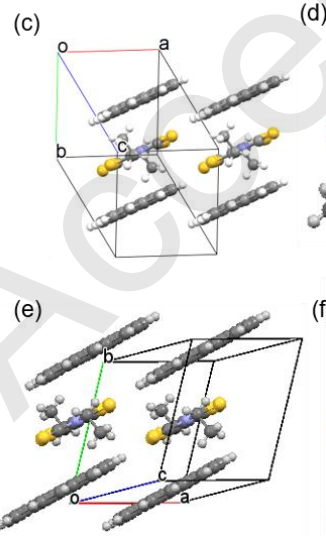

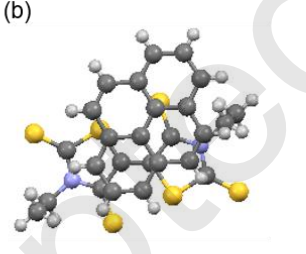

(d)
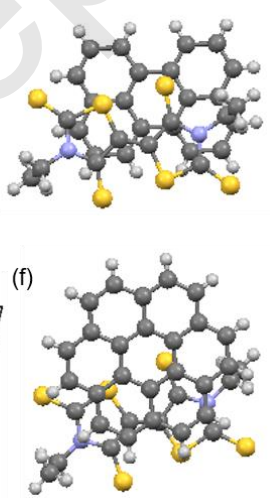

Figure 2. (a) Crystal structure of (pyrene)(SS-Et) viewed along the acceptor long axis, and (b) viewed perpendicular to the molecular plane. (c) Crystal structure of (perylene)(SS-Et) viewed along the acceptor long axis, and (b) viewed perpendicular to the molecular

plane. (d) Crystal structure of (coronene)(SS-Et) viewed along the acceptor long axis, and (e) viewed perpendicular to the molecular plane.

3, are around $3.50 \AA$ in the SS- $\boldsymbol{R}$ and SO- $\boldsymbol{R}$ complexes, but about $3.45 \AA$ in the $\mathbf{O S}-\boldsymbol{R}$ complexes. The difference indicates that the inner $\mathrm{C}=\mathrm{O}$ decreases the $\mathrm{DA}$ spacing slightly. At the same time, SS-Pr complexes have larger DA spacings than SSEt complexes (Table 1); a long alkyl chain increases the interplanar spacings. These tendencies are also observed in neutral SS- $\boldsymbol{R}$ and $\mathbf{O S}-\boldsymbol{R}^{2,3}$

The stack is not the ordinary face-to-face stack but tilted along the molecular short axis (Fig. 2(a)). The neutral SS-R crystals have tilted columns as well $;{ }^{2}$ the adjacent molecules are located in the $0^{\circ}, 30^{\circ}$ and $60^{\circ}$ directions from the molecular plane, ${ }^{21}$ where the ordinary stack corresponds to the $90^{\circ}$ direction. In the present complex, the $30^{\circ}$ interaction is maintained as an AA interaction, and the $0^{\circ}$ interaction is replaced by a DA interaction.

As an exception, (coronene)(SO-Et) has an ordinary $90^{\circ}$ stack (Fig. 5(e)), where the mixed stack does not have a shortaxis offset and only has a long-axis offset (Fig. 5(f)). The stacking axis is the $a$ axis, and the molecular planes are nearly perpendicular to the stacking axis. 
Table 2. Crystallographic data of OS-R and SO-Et complexes.

\begin{tabular}{|c|c|c|c|c|c|c|}
\hline & $\begin{array}{l}\text { (pyrene) } \\
\text { (OS-Et) }\end{array}$ & $\begin{array}{c}\text { (perylene) } \\
(\text { OS-Et) }\end{array}$ & $\begin{array}{c}\text { (perylene) } \\
(\text { OS-Pr) }\end{array}$ & $\begin{array}{l}\text { (pyrene) } \\
\text { (SO-Et) }\end{array}$ & $\begin{array}{c}\text { (perylene) } \\
\text { (SO-Et) }\end{array}$ & $\begin{array}{c}\text { (coronene) } \\
\text { (SO-Et) }\end{array}$ \\
\hline Formula & $\mathrm{C}_{26} \mathrm{H}_{20} \mathrm{~N}_{2} \mathrm{O}_{2} \mathrm{~S}_{4}$ & $\mathrm{C}_{30} \mathrm{H}_{22} \mathrm{~N}_{2} \mathrm{O}_{2} \mathrm{~S}_{4}$ & $\mathrm{C}_{32} \mathrm{H}_{26} \mathrm{~N}_{2} \mathrm{O}_{2} \mathrm{~S}_{4}$ & $\mathrm{C}_{26} \mathrm{H}_{20} \mathrm{~N}_{2} \mathrm{O}_{2} \mathrm{~S}_{4}$ & $\mathrm{C}_{30} \mathrm{H}_{22} \mathrm{~N}_{2} \mathrm{O}_{2} \mathrm{~S}_{4}$ & $\mathrm{C}_{34} \mathrm{H}_{22} \mathrm{~N}_{2} \mathrm{O}_{2} \mathrm{~S}_{4}$ \\
\hline Formula weight & 570.70 & 570.76 & 598.81 & 520.70 & 570.76 & 618.80 \\
\hline Crystal System & triclinic & triclinic & triclinic & triclinic & triclinic & triclinic \\
\hline Space Group & $P-1$ & $P-1$ & $P-1$ & $P-1$ & $P-1$ & $P-1$ \\
\hline Shape & plate & plate & plate & plate & plate & plate \\
\hline$a(\AA)$ & $7.317(4)$ & $7.326(3)$ & $7.365(3)$ & $7.506(4)$ & $7.699(2)$ & $8.640(8)$ \\
\hline$b(\AA)$ & 7.754(14) & $8.145(4)$ & $8.101(8)$ & $7.856(7)$ & $8.464(8)$ & $9.630(5)$ \\
\hline$c(\AA)$ & $11.041(5)$ & $11.233(4)$ & $12.063(4)$ & $10.872(4)$ & $10.046(4)$ & $9.702(5)$ \\
\hline$\alpha$ (deg.) & 104.81(7) & $92.52(3)$ & $88.18(6)$ & $69.79(5)$ & $85.13(5)$ & $107.84(4)$ \\
\hline$\beta$ (deg.) & $101.31(4)$ & 103.51(3) & $82.11(3)$ & $76.82(4)$ & $83.78(3)$ & $108.51(5)$ \\
\hline$\gamma($ deg. $)$ & $91.40(9)$ & $97.61(4)$ & $83.41(6)$ & $89.71(6)$ & $89.63(4)$ & $101.57(6)$ \\
\hline$V\left(\AA^{3}\right)$ & $592(11)$ & $644.0(5)$ & $708.1(8)$ & $583.8(7)$ & $648.4(7)$ & $687.9(9)$ \\
\hline$Z$-value & 1 & 1 & 1 & 1 & 1 & 1 \\
\hline$T(\mathrm{~K})$ & 298 & 298 & 298 & 298 & 298 & 298 \\
\hline$D_{\text {calc }}\left(\mathrm{g} \mathrm{cm}^{-3}\right)$ & 1.460 & 1.472 & 1.404 & 1.481 & 1.462 & 1.494 \\
\hline Total reflns. & 3696 & 4397 & 4827 & 4001 & 4456 & 4724 \\
\hline Unique reflns. & 3460 & 3760 & 4132 & 3417 & 3771 & 4004 \\
\hline$\left(R_{\text {int }}\right)$ & $(0.0731)$ & $(0.0735)$ & $(0.1337)$ & $(0.0766)$ & $(0.1267)$ & $(0.1147)$ \\
\hline$R_{1}\left[F^{2}>2 \sigma\left(F^{2}\right)\right]$ & 0.0896 & 0.0767 & 0.0896 & 0.0550 & 0.0745 & 0.0755 \\
\hline $\begin{array}{l}w R_{2} \text { [All } \\
\text { reflections] }\end{array}$ & 0.2946 & 0.2532 & 0.2326 & 0.1732 & 0.2404 & 0.2391 \\
\hline GOF & 1.009 & 0.967 & 1.049 & 1.017 & 1.004 & 1.085 \\
\hline DA spacing $(\AA)$ & 3.45 & 3.43 & 3.44 & 3.54 & 3.50 & 3.45 \\
\hline
\end{tabular}
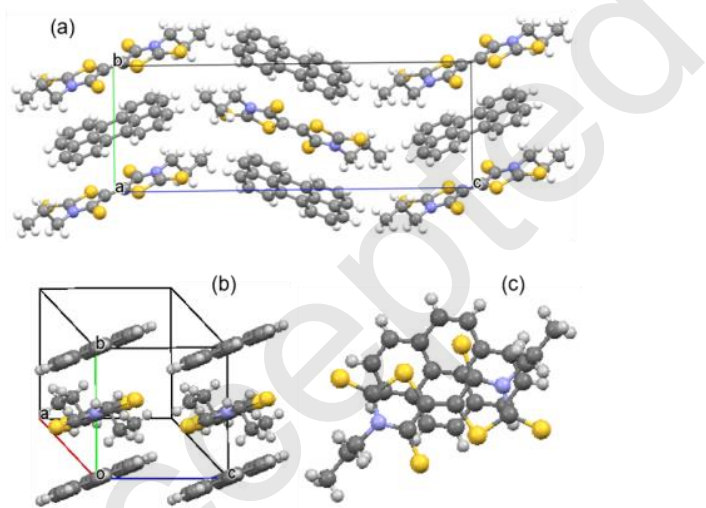

(d)

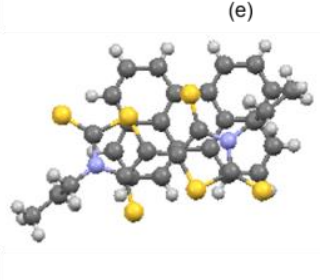

Figure 3. (a) Double-layer structure of (perylene)(SS-Pr). (b) Crystal structure of (pyrene)(SS-Pr) viewed along the acceptor long axis, and (c) viewed perpendicular to the molecular plane. (d) Crystal structure of (perylene)(SS-Pr) viewed along the acceptor long axis, and (e) viewed perpendicular to the molecular plane.
There are large variations in the molecular overlapping mode. When (pyrene)(SS-Et) is viewed perpendicular to the molecular plane (Fig. 2(b)), the pyrene molecule is considerably rotated $\left(63^{\circ}\right)$ from the direction of the central $\mathrm{C}=\mathrm{C}$ bond of the A molecule. The pyrene rotation angles are $11^{\circ}$ in SS-Pr (Fig. 3(c)), $61^{\circ}$ in OS-Et (Fig. 4(b)), and $62^{\circ}$ in SO-Et (Fig. 5(b)). Similar variations of rotation angles are observed in the substituted TCNQ complexes. ${ }^{15,22}$ The large molecular rotation is, however, not an adequate condition of the short-axis offset; for example, (pyrene)(TCNQ) makes an ordinary stack in spite of the large rotation. ${ }^{15,22}$ In the present complex, offset of the molecular center is the origin of the tilted stack (Fig. 2(b)).

For the perylene complexes, the SS-Et molecule of (perylene)(SS-Et) is located on the lower half of the perylene molecule (Fig. 2(d)), which is the origin of the short-axis offset. This is reminiscent of (perylene)(TCNQ). ${ }^{15,23}$ The overlapping pattern is basically the same in other perylene complexes (Figs. 3(e), 4(d), 4(f), and 5(d)). Perylene molecules are almost parallel to the acceptor $\mathrm{C}=\mathrm{C}$ direction, but the rotation is not negligible in $15^{\circ}$ for OS-Et and $9^{\circ}$ for OS-Pr (Figs. 4(d) and 4(f)). 

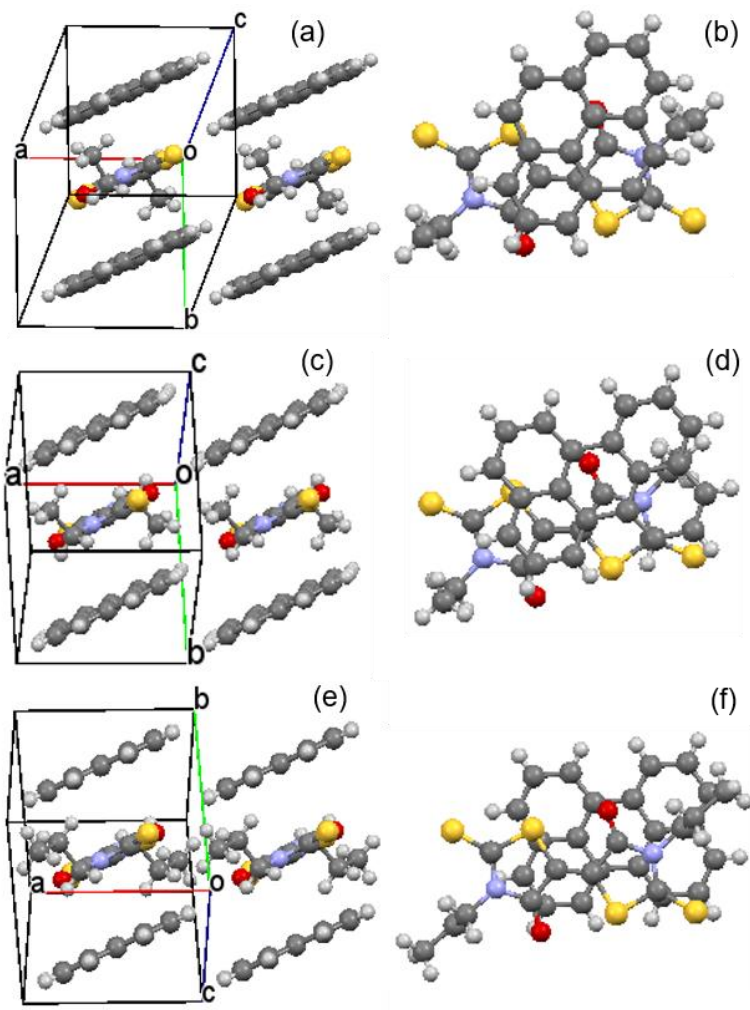

(e)

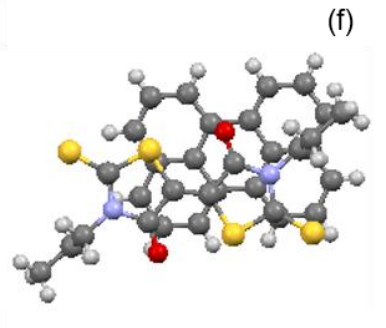

(a)
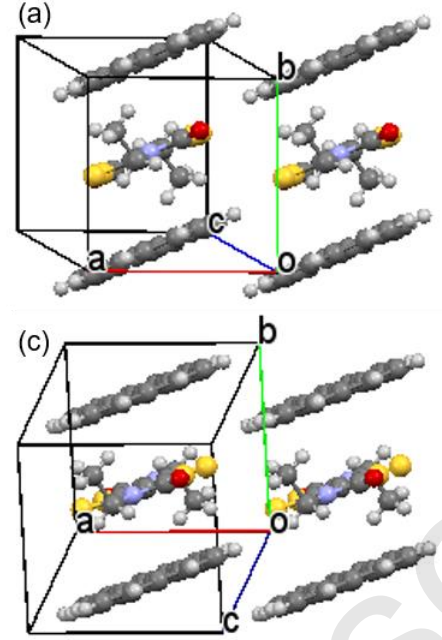

(e)

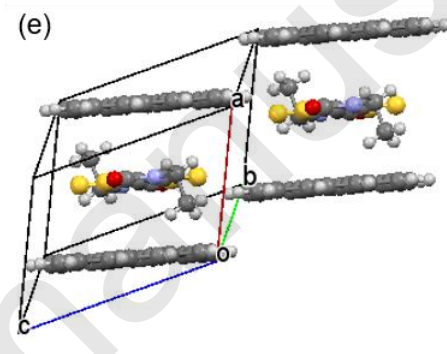

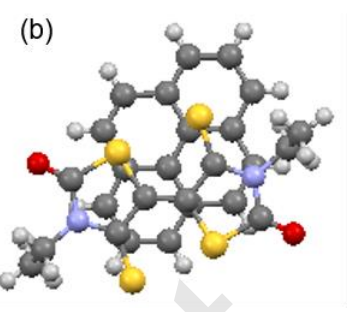
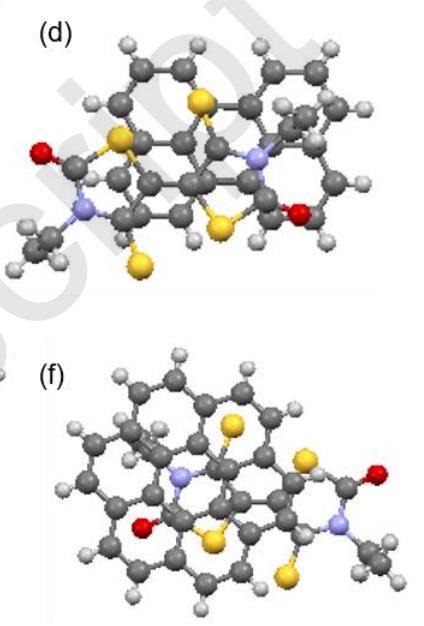

Figure 4. (a) Crystal structure of (pyrene)(OS-Et) viewed along the acceptor long axis, and (b) viewed perpendicular to the molecular plane. (c) Crystal structure of (perylene)(OS-Et) viewed along the acceptor long axis, and (d) viewed perpendicular to the molecular plane. (e) Crystal structure of (perylene)(OS-Pr) viewed along the acceptor long axis, and (f) viewed perpendicular to the molecular plane.

In (coronene)(SS-Et), the molecules are more tilted (Fig. 2(e)) due to the large coronene molecule as reflected in the small $\gamma$ angle (Table 1). The SS-Et molecule is located above the edge of the coronene molecule (Fig. 2(f)). Displacement from the donor center is less than an aromatic ring $(2.8 \AA)$ in perylene, but larger than an aromatic ring in coronene. The largely displaced molecular overlap is similar to (coronene)(TCNQ). ${ }^{24}$ The AA $30^{\circ}$ interaction seems to be maintained by this large displacement (Fig. 2(e)). The molecular long axis of the acceptor is parallel to the coronene armchair edge in the TCNQ complex, but parallel to the zigzag edge in the present complex (only rotated by $13^{\circ}$ ). In (coronene)(SO-Et), the coronene molecule is rotated by $10^{\circ}$ from the direction of the acceptor $\mathrm{C}=\mathrm{C}$ bond (Fig. 5(f)).

(Pyrene)(SS-Pr) and (perylene)(SS-Pr) have a double-layer structure along the molecular long axis (Fig. 3(a)); the $c$ axis is doubled, and the space group is monoclinic (Table 1). The space group of the pyrene compound $(P 21 / n)$ is different from that of the perylene compound $\left(P 2_{1} / c\right)$ due to the alternate

Figure 5. (a) Crystal structure of (pyrene)(SO-Et) viewed along the acceptor long axis, and (b) viewed perpendicular to the molecular plane. (c) Crystal structure of (perylene)(SO-Et) viewed along the acceptor long axis, and (d) viewed perpendicular to the molecular plane. (e) Crystal structure of (coronene)(SO-Et) viewed along the acceptor long axis, and (f) viewed perpendicular to the molecular plane.

arrangement of the columns. In (perylene)(OS-Pr), however, the $c$ axis is not doubled.

Comparing bond lengths with those of neutral SS-Et and SS-Et ${ }^{-}$in $\left[\mathrm{Fe}\left(\mathrm{Cp}^{*}\right)_{2}\right][\mathbf{S S}-\mathbf{E t}],{ }^{5 \mathrm{a}}$ we can estimate charge-transfer degree $\rho$ in the SS-Et complexes (Table S1). The results demonstrate $\rho$ is practically zero. In other cases, bond lengths are also close to the pure acceptors, indicating the basically neutral character of the charge-transfer complexes. This is reasonable in view of the comparatively weak donor ability of the present donors (Fig. 1).

(Perylene)(SS-Et) and (coronene)(SS-Et) respectively have short $\mathrm{S} \cdots \mathrm{S}$ contacts of 3.59 and $3.56 \AA$ in the interchain $\left(30^{\circ}\right)$

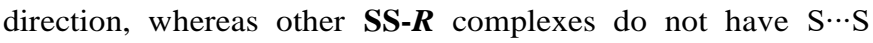
contacts shorter than $3.9 \AA$ (Table 1). OS-R and SO-R complexes do not have any short $\mathrm{S} \cdots \mathrm{S}$ contacts, although (perylene)(SO-Et) has $\mathrm{S} \cdots \mathrm{S}$ contacts of 3.74 and $3.97 \AA$. In (coronene)(SO-Et), intercolumnar AA interaction disappears entirely. This is associated with the ordinary stacking structure coming from the large coronene molecule. 
Table 3. Transistor characteristics of the single-crystal transistors.

\begin{tabular}{|c|c|c|c|c|c|c|}
\hline Compounds & Conditions & Measurement & & $\begin{array}{c}\mu_{\max }\left[\mu_{\text {average }}\right] \\
\left(\mathrm{cm}^{2} \mathrm{~V}^{-1} \mathrm{~s}^{-1}\right)\end{array}$ & $V_{\text {th }}(\mathrm{V})$ & on/off ratio \\
\hline \multirow[t]{4}{*}{ (perylene)(SS-Et) } & Pristine & under vacuum & $\mathrm{e}$ & $0.03\left[4.5 \times 10^{-3}\right]$ & 13 & $4 \times 10^{2}$ \\
\hline & & in air & & 0.05 & -2 & 60 \\
\hline & two months & under vacuum & & 0.03 & 13 & $4 \times 10^{2}$ \\
\hline & under vacuum & in air & & 0.05 & -2 & 60 \\
\hline \multirow[t]{4}{*}{$($ coronene $)($ SS-Et $)$} & Pristine & under vacuum & $\mathrm{e}$ & $3.8 \times 10^{-3}\left[1.9 \times 10^{-3}\right]$ & 15 & $1 \times 10^{5}$ \\
\hline & & in air & & $6.5 \times 10^{-3}$ & 2 & $3 \times 10^{6}$ \\
\hline & two months & under vacuum & & $4.4 \times 10^{-3}$ & 26 & $1 \times 10^{4}$ \\
\hline & under vacuum & in air & & $4.2 \times 10^{-3}$ & 21 & $7 \times 10^{5}$ \\
\hline (pyrene)(SS-Pr) & Pristine & $\begin{array}{l}\text { under vacuum } \\
\text { in air }\end{array}$ & $\mathrm{e}$ & $2.2 \times 10^{-5}$ & -20 & 6 \\
\hline \multirow[t]{8}{*}{ (pyrene)(OS-Et) } & Pristine & under vacuum & $\mathrm{h}$ & $2.1 \times 10^{-3}$ & -40 & $1 \times 10^{4}$ \\
\hline & & & $\mathrm{e}$ & $4.9 \times 10^{-5}$ & -17 & $2 \times 10^{4}$ \\
\hline & & in air & $\mathrm{h}$ & $4.3 \times 10^{-4}$ & -6 & $6 \times 10^{4}$ \\
\hline & & & $\mathrm{e}$ & - & - & - \\
\hline & two months & under vacuum & $\mathrm{h}$ & - & - & 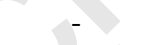 \\
\hline & under vacuum & & $\mathrm{e}$ & $3.9 \times 10^{-4}$ & 30 & $3 \times 10^{4}$ \\
\hline & & in air & $\mathrm{h}$ & $1.8 \times 10^{-4}$ & -54 & $3 \times 10^{3}$ \\
\hline & & & $\mathrm{e}$ & $2.1 \times 10^{-4}$ & 10 & $9 \times 10^{4}$ \\
\hline \multirow[t]{8}{*}{$($ perylene $)(\mathbf{O S}-\mathbf{E t})$} & Pristine & under vacuum & $\mathrm{h}$ & $0.012\left[4.9 \times 10^{-3}\right]$ & 8 & $7 \times 10^{2}$ \\
\hline & & & $\mathrm{e}$ & $7.5 \times 10^{-3}\left[1.8 \times 10^{-3}\right]$ & 29 & $3 \times 10^{4}$ \\
\hline & & in air & $\mathrm{h}$ & $4.1 \times 10^{-3}\left[3.9 \times 10^{-3}\right]$ & 1 & $6 \times 10^{4}$ \\
\hline & & & $\mathrm{e}$ & $1.7 \times 10^{-3}\left[1.2 \times 10^{-3}\right]$ & 22 & $2 \times 10^{4}$ \\
\hline & two months & under vacuum & $\mathrm{h}$ & $2.5 \times 10^{-3}\left[9.5 \times 10^{-4}\right]$ & 3 & $1 \times 10^{3}$ \\
\hline & under vacuum & & $\mathrm{e}$ & $1.5 \times 10^{-3}\left[4.6 \times 10^{-4}\right]$ & 40 & $2 \times 10^{4}$ \\
\hline & & in air & $\mathrm{h}$ & $7.0 \times 10^{-3}\left[1.9 \times 10^{-3}\right]$ & 3 & $4 \times 10^{4}$ \\
\hline & & & $\mathrm{e}$ & $6.2 \times 10^{-4}\left[3.2 \times 10^{-4}\right]$ & 53 & $3 \times 10^{4}$ \\
\hline \multirow[t]{4}{*}{ (perylene)(OS-Pr) } & Pristine & under vacuum & $\mathrm{h}$ & $7.8 \times 10^{-4}\left[6.8 \times 10^{-4}\right]$ & -27 & $4 \times 10^{5}$ \\
\hline & & in air & & $8.2 \times 10^{-5}$ & -23 & $8 \times 10^{3}$ \\
\hline & two months & under vacuum & & $3.2 \times 10^{-5}$ & -32 & $2 \times 10^{3}$ \\
\hline & under vacuum & in air & & $5.0 \times 10^{-5}$ & -28 & $3 \times 10^{3}$ \\
\hline \multirow[t]{4}{*}{ (pyrene)(SO-Et) } & Pristine & under vacuum & $\mathrm{h}$ & $2.6 \times 10^{-4}$ & -13 & $8 \times 10^{3}$ \\
\hline & & in air & & $4.8 \times 10^{-4}$ & -24 & $1 \times 10^{4}$ \\
\hline & two months & under vacuum & & $1.2 \times 10^{-4}$ & -30 & $7 \times 10^{3}$ \\
\hline & under vacuum & in air & & $1.7 \times 10^{-4}$ & -58 & $2 \times 10^{2}$ \\
\hline \multirow[t]{8}{*}{ (perylene)(SO-Et) } & Pristine & under vacuum & $\mathrm{h}$ & $2.0 \times 10^{-3}\left[7.9 \times 10^{-4}\right]$ & 19 & $6 \times 10^{2}$ \\
\hline & & 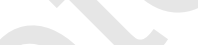 & $\mathrm{e}$ & $2.4 \times 10^{-4}\left[1.5 \times 10^{-4}\right]$ & 60 & $4 \times 10^{3}$ \\
\hline & & in air & $\mathrm{h}$ & $1.7 \times 10^{-3}\left[1.4 \times 10^{-3}\right]$ & -3 & $3 \times 10^{2}$ \\
\hline & & & $\mathrm{e}$ & $1.2 \times 10^{-4}\left[9.2 \times 10^{-5}\right]$ & -20 & $2 \times 10^{3}$ \\
\hline & two months & under vacuum & $\mathrm{h}$ & $6.9 \times 10^{-4}\left[5.3 \times 10^{-4}\right]$ & 29 & $2 \times 10^{3}$ \\
\hline & under vacuum & 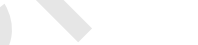 & $\mathrm{e}$ & $4.7 \times 10^{-4}\left[4.2 \times 10^{-4}\right]$ & 13 & $9 \times 10^{3}$ \\
\hline & & in air & $\mathrm{h}$ & $1.1 \times 10^{-3}\left[6.1 \times 10^{-4}\right]$ & 2 & $7 \times 10^{4}$ \\
\hline & & & $\mathrm{e}$ & $5.2 \times 10^{-4}\left[4.8 \times 10^{-4}\right]$ & -5 & $4 \times 10^{3}$ \\
\hline
\end{tabular}

In summary, these complexes generally have mixed stacks tilted along the molecular short axis. This tilted structure resembles the neutral SS- $\boldsymbol{R}$ structure. The OS- $\boldsymbol{R}$ and SO- $\boldsymbol{R}$ complexes realize the same structure as well, though neutral OS- $\boldsymbol{R}$ and SO-R have herringbone structures. Accordingly, the SS- $\boldsymbol{R}$ crystals maintain short $\mathrm{S} \cdots \mathrm{S}$ contacts in the $30^{\circ}$ direction, whereas similar $\mathrm{S} \cdots \mathrm{S}$ interactions are absent in the OS-R and SO-R complexes.

\section{Transistor characteristics}

Characteristics of (perylene)(SS-Et) and (coronene)(SS-Et) single-crystal transistors are shown in Fig. 6. These complexes exhibit n-channel transistor properties. From these characteristics, the transistor parameters are extracted as listed in Table 3. The perylene compound shows electron mobility of $0.05 \mathrm{~cm}^{2} \mathrm{~V}^{-1} \mathrm{~s}^{-1}$. The transistor characteristics are maintained in air, indicating the excellent air stability. The performance does not drop even after two months. In contrast, (pyrene)(SS-Pr) shows much reduced transistor properties.

(Perylene)(OS-Et) shows ambipolar transistor properties (Fig. 7). The hole mobility is slightly larger than the electron mobility, and amounts to $0.012 \mathrm{~cm}^{2} \mathrm{~V}^{-1} \mathrm{~s}^{-1}$, which is comparable to the electron mobility of (perylene)(SS-Et). The hole dominance is also obvious from the output characteristics; 
(a)

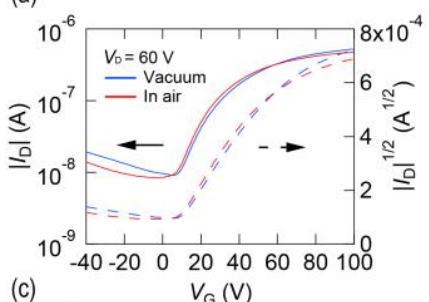

(b)

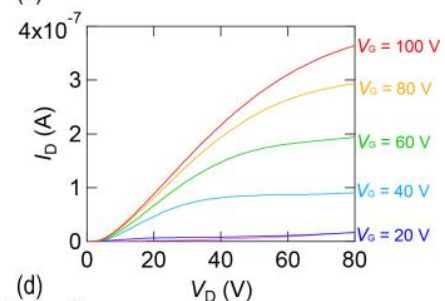

(d)
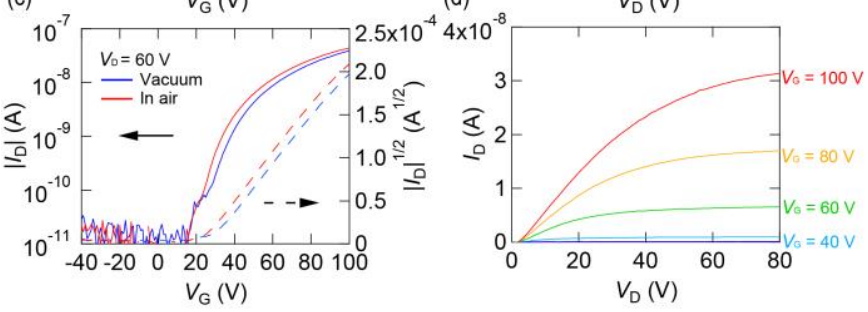

Figure 6. (a) Transfer characteristics of a (perylene)(SS-Et) singlecrystal transistor measured under vacuum (blue) and in air (red), where the channel length/width are $L / W=113 / 165 \mu \mathrm{m}$. (b) Output characteristics of a (perylene)(SS-Et) single-crystal transistor measured under vacuum. (c) Transfer characteristics of a (coronene) (SS-Et) single-crystal transistor measured under vacuum (blue) and in air (red), where $L / W=117 / 112 \mu \mathrm{m}$. (d) Output characteristics of a (coronene)(SS-Et) single-crystal transistor measured under vacuum.

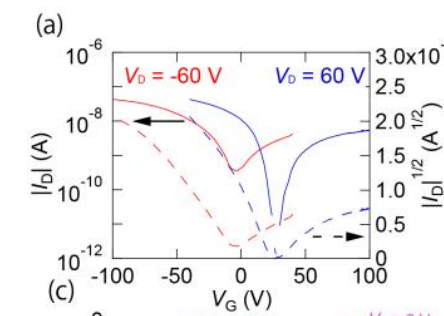

(b)
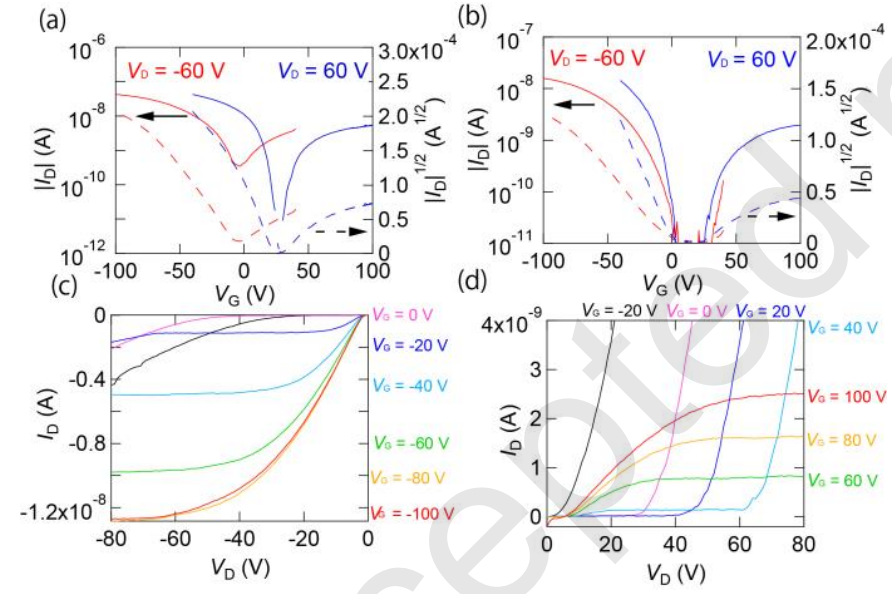

Figure 7. Transfer characteristics of a (perylene)(OS-Et) single-crystal transistor measured (a) under vacuum, and (b) in air, where $L / W=$ $165 / 20 \mu \mathrm{m}$. (c,d) Transfer characteristics of a (perylene)(OS-Et) singlecrystal transistor measured under vacuum.

a remarkable reversed hole-transporting region appears in Fig. 7(d). The difference of the electron and hole threshold voltages $V_{\text {th }}$ is around $20 \mathrm{~V}$; the comparatively small value is characteristic of two-component systems. ${ }^{15,25}$ However, not only the electron mobility but also the hole mobility drop significantly in air (Fig. 7(b)). The drop of the electron transport is particularly significant. This is the same as OS-R. ${ }^{2}$ Therefore, the air-stable n-channel performance of the SS-Et compounds is ascribed to SS-Et.

(Pyrene)(OS-Et) and (perylene)(SO-Et) exhibit ambipolar transistor properties as well, while the electron mobility is one order of magnitude smaller than the hole mobility. In (perylene)(OS-Pr) and (pyrene)(SO-Et), only the hole mobility is estimated. Since even the hole mobilities $\left(<10^{-3} \mathrm{~cm}^{2} \mathrm{~V}^{-1} \mathrm{~s}^{-1}\right)$ are smaller than the former two $\left(>10^{-3} \mathrm{~cm}^{2} \mathrm{~V}^{-1} \mathrm{~s}^{-1}\right)$, the electron transport is considered to be not large enough to be estimated. Therefore, transistor properties of these OS-Et and SO-Et complexes are basically regarded as hole-dominant ambipolar transport. In the OS-Et compounds, even the hole mobility significantly drops in air, whereas the hole mobility of the SOEt compounds is relatively stable. This is in agreement with the slightly stronger acceptor ability of SO-Et $(-3.9 \mathrm{eV})$ than OS-Et $(-3.8 \mathrm{eV})$.

\section{Transfer integrals}

In order to understand the observed transport properties, transfer integrals are investigated. Interstack AA and DD transfers are evaluated from the splitting of the A LUMO or the D HOMO in the dimers (Table 4). In addition, estimations from the overlap of frozen orbitals are listed. ${ }^{21}$

In (perylene)(SS-Et) and (coronene)(SS-Et), $t_{\mathrm{AA}}$ is significantly large, and $t_{\mathrm{DD}}$ is smaller than $t_{\mathrm{AA}}$. These two compounds have $\mathrm{S} \cdots \mathrm{S}$ contacts shorter than $3.6 \AA$, whereas the other three SS- $\boldsymbol{R}$ complexes do not have S $\cdots$ S contacts shorter than $3.9 \AA$ (Table 1). Hence large $t_{\mathrm{AA}}$ is obviously related to the $\mathrm{S} \cdots \mathrm{S}$ contacts. The former two compounds show reasonable transistor properties. Electron transport observed in the SS- $\boldsymbol{R}$ compounds is closely related to the direct AA interaction.

In the OS- $\boldsymbol{R}$ and SO- $\boldsymbol{R}$ compounds, $t_{\mathrm{AA}}$ vanishes, but moderate $t_{\mathrm{DD}}$ remains. This is consistent with the observed hole-dominant transport. Both $t_{\mathrm{AA}}$ and $t_{\mathrm{DD}}$ are very small in (coronene)(SO-Et), while this compound does not show transistor properties. This comes from the ordinary stacking structure, where each component is comparatively isolated.

In order to investigate the transport in the mixed stacks, we have estimated $t_{\mathrm{e}} \mathrm{eff}^{\text {eff }} t_{\mathrm{h}}{ }^{\text {eff }}$ from the triads (Table 4). However, these values $(<10 \mathrm{meV})$ are significantly smaller than the ordinary mixed stacks $(\sim 60 \mathrm{meV}) .{ }^{13}$ This is not surprising because $t_{\mathrm{DA}}(<1 \mathrm{meV})$ is smaller than the ordinary stacks $(\sim 300$ $\mathrm{meV}) .{ }^{13}$ LUMO of SS- $\boldsymbol{R}$ has low-symmetry many-node structures (Fig. 1(a)), and orbital overlap with the donor HOMO is expected to be small. In addition, the overlap modes have generally low symmetry. Not only $t_{\mathrm{DA}}$ between the $\mathrm{D}$ HOMO and the A LUMO, but also other intrastack transfers are small in general, and the resulting $t_{\mathrm{e}}{ }^{\text {eff }}$ and $t_{\mathrm{h}}{ }^{\text {eff }}$ are small.

SS- $\boldsymbol{R}$ is a characteristic molecule due to the low symmetry and the strong $\mathrm{S} \cdots \mathrm{S}$ contacts directed to particular orientations. As a result, transport along the mixed stack is not the major pathway, but the direct AA interaction is the most important interaction. Electron transport in the present SS- $\boldsymbol{R}$ complexes is not so small among mixed-stack complexes (typically at most $\left.0.1 \mathrm{~cm}^{2} \mathrm{~V}^{-1} \mathrm{~s}^{-1}\right)$. However, when $\mathbf{S S}-\boldsymbol{R}$ is replaced by $\mathbf{O S}-\boldsymbol{R}$, even the charge polarity changes entirely. The observed 
Table 4. Calculated transfer integrals $(\mathrm{meV})$.

\begin{tabular}{|c|c|c|c|c|c|}
\hline \multirow[t]{2}{*}{ Complex } & \multicolumn{3}{|c|}{$t(\mathrm{meV})^{\mathrm{a}}$} & \multicolumn{2}{|c|}{$t_{\mathrm{e}}{ }^{\mathrm{eff}} / t_{\mathrm{h}}{ }^{\mathrm{eff}}(\mathrm{meV})$} \\
\hline & AA & DD & DA & Triad & Partition \\
\hline (pyrene)(SS-Et) & $44(15)$ & $110(20)$ & $(0.1)$ & $9 / 7$ & $4 / 1$ \\
\hline (perylene)(SS-Et) & $195(78)$ & $82(16)$ & $(0.7)$ & $1 / 13$ & $2 / 1$ \\
\hline (coronene)(SS-Et) & $216(88)$ & $117(25)$ & (12.8) & $1 / 5$ & $8 / 1$ \\
\hline (pyrene)(SS-Pr) & $13(100)$ & $62(27)$ & $(0.6)$ & $2 / 8$ & $12 / 8$ \\
\hline (perylene)(SS-Pr) & $5(4)$ & $56(8)$ & $(0.4)$ & $2 / 19$ & $1 / 8$ \\
\hline (pyrene)(OS-Et) & $3(0.6)$ & $66(14)$ & $(0.5)$ & $7 / 8$ & $2 / 2$ \\
\hline (perylene)(OS-Et) & $4(0.5)$ & $19(0)$ & $(1.2)$ & $7 / 14$ & $2 / 2$ \\
\hline (perylene)(OS-Pr) & $1(0.1)$ & $50(7)$ & $(0.7)$ & $6 / 13$ & $2 / 2$ \\
\hline (pyrene)(SO-Et) & $44(17)$ & $46(9)$ & $(0.1)$ & $5 / 17$ & $0 / 5$ \\
\hline$($ perylene $)(\mathbf{S O}-\mathbf{E t})$ & $27(0.3)$ & $55(2)$ & $(0.7)$ & $12 / 16$ & $6 / 13$ \\
\hline (coronene) (SO-Et) & $4(0)$ & $12(1)$ & $(1.8)$ & $7 / 5$ & $5 / 2$ \\
\hline
\end{tabular}

${ }^{a}$ From the HOMO (DD) or LUMO (AA) splitting of the dimers. Values in the parentheses are from the frozen orbital approximation.

mobility seems to be related to the largest transfers among $t_{\mathrm{AA}}$, $t_{\mathrm{DD}}$, and $t_{\mathrm{e}}^{\text {eff }}$ (Fig. S5). Although the interchain interactions mainly mediate the charge transport, the polarity switching appears even in the transistor properties measured in the stacking direction.

\section{Conclusions}

Crystal structures of eleven charge-transfer cocrystals containing SS- $\boldsymbol{R}, \mathbf{O S}-\boldsymbol{R}$, and SO- $\boldsymbol{R}$ are determined. These complexes have mixed stacks with short-axis offset. This is associated with the characteristic $\mathrm{S} \cdots \mathrm{S}$ contacts between the SS$\boldsymbol{R}$ molecules that have the same geometry as the neutral SS- $\boldsymbol{R}$ crystals. There are a large variety of overlap modes and rotation angles in the stacks. Coronene leads to irregular structures; (coronene)(SS-Et) has largely tilted molecules, and (coronene)(SO-Et) has ordinary stacks.

Single-crystal transistors of SS- $\boldsymbol{R}$ complexes show electron transport. This is due to the direct interchain AA interaction mediated by the $\mathrm{S} \cdots \mathrm{S}$ contacts. When the $\mathrm{S} \cdots \mathrm{S}$ contacts are lost, the OS- $\boldsymbol{R}$ and SO-R compounds exhibit hole-dominant ambipolar transport. Even among the SS- $\boldsymbol{R}$ complexes, those without short $\mathrm{S} \cdots \mathrm{S}$ contacts do not have large $t_{\mathrm{AA}}$, and do not show transistor properties. The $\mathrm{n}$-channel transistor properties are air stable in the SS- $\boldsymbol{R}$ compounds, but not in the OS- $\boldsymbol{R}$ and SO- $\boldsymbol{R}$ compounds; the device air stability is similar to the parent acceptors.

It is characteristic of these compounds that the intracolumnar transfers are not most important, but the direct interchain AA interactions are the dominant factor. This should be related to the comparatively low symmetry of the acceptor molecules as well as the characteristic S $\cdots \mathrm{S}$ interactions. The observed transistor properties are exceptional among mixedstack compounds, but the present example demonstrates a case in which only one component is overwhelming in determining the transport properties.

\section{Acknowledgements}

This work was partly supported by JSPS KAKENHI Grant Number 18H02044, and Takahashi Industrial and Economic Research Foundation.

\section{Notes and references}

a Department of Materials Science and Engineering, Tokyo Institute of Technology, O-okayama 2-12-1, Meguro-ku, 152-8552, Japan. E-mail: mori.t.ae@m.titech.ac.jp

${ }^{b}$ Univ Rennes, CNRS, ISCR (Institut des Sciences Chimiques de Rennes) - UMR 6226, F-35000 Rennes, France.

$\dagger$ Electronic supporting information (ESI) available: CCDC 19322111932221 contain the supplementary crystallographic information. Additional information for structure analysis, selected bond lengths, transistor characteristics, and transfer calculations.

1 A. Filatre-Furcate, T. Higashino, D. Lorcy and T. Mori, J. Mater. Chem. C, 2015, 3, 3569 .

2 K. Iijima, Y. Le Gal, T. Higashino, D. Lorcy and T. Mori, J. Mater. Chem. C, 2017, 5, 9121.

3 K. Iijima, Y. Le Gal, D. Lorcy and T. Mori, RSC Adv., 2018, 8, 18400.

4 (a) N. Tenn, N. Bellec, O. Jeannin, L. Piekara-Sady, P. Auban- Senzier, J. Iñiguez, E. Canadell and D. Lorcy J. Am. Chem. Soc., 2009, 131, 16961; (b) Y. Le Gal, T. Roisnel, P. Auban-Senzier, T. Guizouarn and D. Lorcy, Inorg. Chem., 2014, 53, 8755; (c) A. Filatre-Furcate, T. Roisnel, M. Fourmigue, O. Jeannin, N. Bellec, P. Auban-Senzier and D. Lorcy, Chem. Eur. J., 2017, 23, 16004; (c) Y. Le Gal, T. Roisnel, P. Auban-Senzier, N. Bellec, J. Íñiguez, E. Canadell and D. Lorcy, J. Am. Chem. Soc., 2018, 140, 6998.

5 (a) Y. Le Gal, N. Bellec, F. Barrière, R. Clérac, M. Fourmigué, V. Dorcet, T. Roisnel and D. Lorcy, Dalton Trans., 2013, 42, 16672; (b) Y. Le Gal, D. Ameline, N. Bellec, A. Vacher, T. Roisnel, V. Dorcet, O. Jeannin and D. Lorcy, Org. Biomol. Chem., 2015, 15, 8479; (c) Y. Le Gal, M. Rajkumar, A. Vacher, V. Dorcet, T. Roisnel, M. Fourmigué, F. Barrière, T. Guizouarn and D. Lorcy, CrystEngComm, 2016, 18, 3925.

6 (a) K. P. Goetz, D. Vermeulen, M. E. Payne, C. Kloc, L. E. Mcneil and O. D. Jurchescu, J. Mater. Chem. C, 2014, 2, 3065; (b) J. Zhang, W. Xu, P. Sheng, G. Zhao and D. Zhu, Acc. Chem. Res., 2017, 50, 1654; (c) H. Jiang, P. Hu, K. K. Zhang, Y. Long, W. Hu and C. Kloc, J. Mater. Chem. C, 2018, 6, 1884; (d) T. Mori, Chem. Lett., 2011, 40, 428. 
7 (a) B. Lüssem, M. Riede and K. Leo, Phys. Status Solidi A, 2013, 210, 9; (b) I. Salzmann, G. Heimel, M. Oehzelt, S. Winkler and N. Koch, Acc. Chem. Res., 2016, 49, 370.

8 J. Zhang, J. Jin, H. Xu, Q. Zhang and W. Huang, J. Mater. Chem. C, 2018, 6, 3485.

9 (a) Y. Zhao, Y. Guo and Y. Liu, Adv. Mater., 2013, 25, 5372; (b) Y. Olivier, D. Niedzialek, V. Lemaur, W. Pisula, K. Müllen, U. Koldemir, J. R. Reynolds, R. Lazzaroni, J. Cornil and D. Beljonne, Adv. Mater., 2014, 26, 2119; (c) J. Choi, H. Song, N. Kim and F. S. Kim, Semicond. Sci. Technol., 2015, 30, 64002; (d) L. Lu, T. Zheng, Q. Wu, A. M. Schneider, D. Zhao and L.Yu, Chem. Rev., 2015, 115, 12666; (e) C. Cheng, H. Geng, Y. Yi and Z. Shuai, J. Mater. Chem. C, 2017, 5, 3247.

10 (a) L. Zhu, Y. Yi, Y. Li, E.-G. Kim, V. Coropceanu and V. J.-L. Brédas, J. Am. Chem. Soc., 2012, 134, 2340; (b) L. Zhu, Y. Yi, A. Fonari, N. S. Corbin, V. Coropceanu and J.-L. Brédas, J. Phys. Chem. C, 2014, 118, 14150 .

11 (a) J. Tsutsumi, S. Matsuoka, S. Inoue, H. Minemawari, T. Yamada and T. Hasegawa, J. Mater. Chem. C, 2015, 3, 1976; (b) Y. Shibata, J. Tsutsumi, S. Matsuoka, K. Matsubara, Y. Yoshida, M. Chikamatsu and T. Hasegawa, Appl. Phys. Lett., 2015, 106, 143303; (c) T. Higashino, M. Dogishi, T. Kadoya, R. Sato, T. Kawamoto and T. Mori, T. J. Mater. Chem. C, 2016, 4, 5981; (d) R. Sato, M. Dogishi, T. Higashino, T. Kadoya, T. Kawamoto and T. Mori, J. Phys. Chem. C, 2017, 121, 6561.

12 (a) H. Geng, X. Zheng, Z. Shuai, L. Zhu and Y. Yi, Adv. Mater., 2015, 27, 1443; (b) L. Zhu, H. Geng, Y. Yi and Z. Wei, Phys. Chem. Chem. Phys., 2017, 19, 4418.

13 (a) R. Sato, T. Kawamoto and T. Mori, J. Mater. Chem. C, 2019, 7, 567; (b) K. Iijima, R. Sanada, D. Yoo, R. Sato, T. Kawamoto and T. Mori, ACS Applied Mater. Interfaces, 2018, 30, 10262.

14 (a) R. Sato, D. Yoo and T. Mori, CrysEngComm, 21, 3218 (2019); (b) R. Sato, D. Yoo, T. Higashino and T. Mori, Chem. Lett., 2019, 48, 264.

15 R. Sanada, D. Yoo, R. Sato, K. Iijima, T. Kawamoto and T. Mori, J. Phys. Chem. C, 123, 12088 (2019).

16 (a) M.-H. Yoon, H. Yan, A. Facchetti and T. J. Marks, J. Am. Chem. Soc., 2005, 127, 10388; (b) S. Tamura, T. Kadoya, T. Kawamoto and T. Mori, Appl. Phys. Lett., 2013, 102, 63305.

17 K.-J. Baeg, Y.-Y. Noh, J. Ghim, B. Lim and D.-Y. Kim, Adv. Funct. Mater., 2008, 18, 3678.

18 Y. Kawasugi, H. M. Yamamoto, M. Hosoda, N. Tajima, T. Fukunaga, K. Tsukagoshi and R. Kato, Appl. Phys. Lett., 2008, 92, 243508.

19 ADF2017.109; Scientific Computing \& Modeling (SCM). Theoretical Chemistry; Vrije Universiteit: Amsterdam, The Netherlands. http://www.scm.com.

20 (a) M. J. S. Dewar, E. G. Zoebisch, E. F. Healy and J. J. P. Stewart, J. Am. Chem. Soc., 1985, 107, 3902.

21 T. Mori, A. Kobayashi, Y. Sasaki, H. Kobayashi, G. Saito and H. Inokuchi, Bull. Chem. Soc. Jpn., 1984, 57, 627.

22 (a) C. K. Prout, I. J. Tickle and J. D. Wright, J. Chem. Soc. Perkin 2, 1973, 528. (b) Q. Zhang, CSD Commun., 2018, DOI: 10.5517/ ccdc.csd.cc1zybx5, CCDC 1845458.

23 (a) I. J. Tickle and C. K. Prout, J. Chem. Soc. Perkin 2, 1973, 720; (b) D. Vermeulen, L. Y. Zhu, K. P. Goetz, P. Hu, H. Jiang, C. S. Day, O. D. Jurchescu, V. Coropceanu, C. Kloc and L. E. McNeil, J. Phys. Chem. C, 2014, 118, 24688.

24 (a) X. Chi, C. Besnard, V. K. Thorsmolle, V. Y. Butko, A. J. Taylor, T. Siegrist and A. P. Ramirez, Chem. Mater., 2004, 16, 5751; (b) J. Zhang, G. Liu, Y. Zhou, G. Long, P. Gu and Q. Zhang, ACS Appl. Mater. Interfaces, 2017, 9, 1183.

25 O. Pitayatanakul, T. Higashino, M Tanaka, H. Kojima, M. Ashizawa, T. Kawamoto, M. Matsumoto, K. Ishikawa and T. Mori, J. Mater. Chem. C, 2014, 2, 9311. 